\title{
Endowment Effects in Contests
}

\author{
Curtis R. Price ${ }^{*}$ and Roman M. Sheremeta ${ }^{* *}$ \\ * Department of Economics \& Finance, College of Business, University of Southern Indiana, \\ 8600 University Blvd., Evansville, IN 47712 \\ **Argyros School of Business and Economics, Chapman University, \\ One University Drive, Orange, CA 92866, U.S.A.
}

July 8, 2009

\begin{abstract}
We design an experiment to test if the manner in which subjects receive the endowment has any bearing on the amount of overbidding in contests. We find that overbidding is significantly higher when subjects are given a large per-experiment endowment rather than when the endowment is given per-period. Risk-aversion and non-monetary utility of winning play important roles in explaining our findings.
\end{abstract}

JEL Classifications: C72, C91, D72

Keywords: rent-seeking, contest, experiments, overbidding, endowment

Corresponding author: Roman M. Sheremeta; E-mail: sheremet@chapman.edu

We want to thank Tim Cason, Will Masters, as well as seminar participants at Purdue University and participants at the June 2009 Economic Science Association meeting for helpful comments. This research has been supported by National Science Foundation Grant. Any remaining errors are ours.

\section{Introduction}


Contests are games in which players compete in order to win a prize. It is well documented in experimental contest literature that subjects overbid relative to Nash equilibrium predictions and thus they incur substantial losses (Morgan et al., 2008). A number of studies have tried to identify means by which overbidding can be reduced. To date, researchers have found that overbidding decreases with the repetition of the contest (Davis and Reilly, 1998), groups make lower bids than individuals (Sheremeta and Zhang, 2009), and constraining individual endowments reduces overbidding (Sheremeta, 2009). This last study suggests that a portion of overbidding can be attributed to the size of the endowment i.e., endowment effects.

The purpose of this paper is to study the amount of overbidding in contests when the endowment is given at the beginning of each contest (per-period) versus a single equivalent endowment given at the beginning of the sequence of contests (per-experiment). We find that overbidding is significantly higher when subjects are given the large per-experiment endowment than when the endowment is given per-period. Risk-aversion and non-monetary utility of winning play important roles in explaining our findings.

\section{Theoretical Model}

We consider a lottery contest with $N$ identical risk-neutral players with initial endowment levels $W$. Player $i$ chooses his bid, $b_{i}$, to win the prize of value $V$. The probability that a player $i$ wins the prize, $p_{i}\left(b_{i}, b_{-i}\right)$, is given by the lottery contest success function:

$$
p_{i}\left(b_{i}, b_{-i}\right)=b_{i} / \sum_{j} b_{j} \text {. }
$$

That is, the probability of winning depends on player $i$ 's own bid relative to the sum of all player's bids. Given (1), the expected payoff for player $i, E\left(\pi_{i}\right)$, can be written as

$$
E\left(\pi_{i}\right)=p_{i}\left(W+V-b_{i}\right)+\left(1-p_{i}\right)\left(W-b_{i}\right)=p_{i} V-b_{i}+W .
$$


Differentiating (2) with respect to $b_{i}$ and accounting for the symmetric Nash equilibrium leads to the classic solution (Tullock, 1980),

$$
b^{*}=V(N-1) / N^{2} .
$$

\section{Experimental Design and Procedures}

Two commonly used protocols in experimental studies of contests are per-experiment and per-period endowments. We refer to the "per-experiment" protocol as "E" and the "perperiod" as "P”. The E protocol has been used by Davis and Reilly (1998), Barut et al. (2002), Gneezy and Smorodinsky (2006), and Noussair and Jonathon (2006). In these studies, each subject receives a large participation fee, announced at the beginning of the experiment. This participation fee can be used to pay off any losses incurred during the series of contests. The P protocol has been used by Potters et al. (1998), Anderson and Stafford (2003), Morgan et al. (2008), and Sheremeta and Zhang (2009). Under the P protocol, each subject receives a small per-period endowment which can be used to make bids in that period of the experiment. At the beginning of the next period, subjects receive a new endowment and bidding again occurs. No endowment from the previous period is allowed to be carried over.

In each treatment of our experiment, there are 4 players $(N=4)$ competing with each other for the prize which is valued at 120 experimental francs $(V=120)$. From (2) and (3), we see that the equilibrium bid is 22.5 and the expected payoff is 7.5. In the E treatment, subjects receive a show up fee of $\$ 10$ (equivalent to 600 francs) to play a contest for 30 periods, 5 of which are randomly selected for payment at the end of the experiment. In the P treatment, instead of a show up fee, subjects receive a per-period endowment of 120 francs to play a contest for 30 periods. Again, 5 out of the thirty periods are randomly selected for payment at the end of 
the experiment. An important aspect of the design is the equivalence of the two endowment types. Although we cannot rule out any perceived differences the subjects may have about the $\mathrm{E}$ and $\mathrm{P}$ endowments, we can argue that the two endowments are quantitatively similar. For example, a subject who chooses to make no bids earns the same under the two endowments. Additionally, there are no theoretical differences between the two treatments since the endowment does not enter the equilibrium bid (3). Consequentially, there is no reason a-priori that the subject's bidding behavior would vary across the two treatments.

The experiment involved 96 undergraduate subjects from Purdue University. The computerized experimental sessions were run using z-Tree (Fischbacher, 2007). We ran 4 sessions of the E treatment and 4 sessions of the P treatment. In each session, there were a total of 12 subjects and the session proceeded in three parts. Instructions were given to subjects at the beginning of each part and the experimenter read the instructions aloud. ${ }^{1}$

In the first part, subjects made 15 choices in simple lotteries, similar to Holt and Laury (2002). ${ }^{2}$ This method was used to elicit subjects' risk preferences. In the second part, subjects participated in a total of 30 periods of the bidding contest. At the beginning of each period, subjects were randomly re-grouped to form a 4-player group. Subjects were then allowed to make bids between 0 and 120 for a prize of 120 francs. After all subjects submitted their bids, the computer chose the winner by implementing a simple lottery rule: the chance of receiving the prize is calculated by the number of francs a subject bids divided by the total number of francs all 4 subjects in the group bid. In the third part of the experiment, subjects were asked to bid for a prize with a value of zero francs. Subjects were told that they would be informed whether they

\footnotetext{
${ }^{1}$ Instructions are available upon request.

${ }^{2}$ Subjects were asked to state whether they preferred safe option A or risky option B. Option A yielded \$1 payoff with certainty, while option B yielded a payoff of either $\$ 3$ or $\$ 0$. The probability of receiving $\$ 3$ or $\$ 0$ varied across all 15 lotteries.
} 
won the contest or not and that all subjects would have to pay their bids. This procedure was used to measure how important it is for subjects to win when winning is costly and there is no monetary reward for winning.

At the conclusion of the experiment, 1 of the 15 lottery choices subjects made in part one was randomly selected for payment. Subjects were also paid for 5 of the 30 periods in part two and for the 1 decision they made in part three. The earnings were converted into US dollars at the rate of 60 francs to $\$ 1$. Average earnings were $\$ 12$ per subject and the experiment lasted for about 40 minutes.

\section{Results}

Table 4.1 summarizes average bids and payoffs. Overall, subjects in both treatments significantly overbid relative to the risk-neutral Nash equilibrium prediction (for both treatments $p$-value $<0.01) .^{3}$ The difference is also significant when we run Wilcoxon signed-rank tests for the bids made in the first period ( $p$-value $<0.01)$. As a result of significant overbidding, average payoffs are negative. In the E treatment subjects receive the average payoff of -12.8 and in the $\mathrm{P}$ treatment they receive -22.2 .

It is often argued that subjects need to get some experience in order to learn how to play the equilibrium. For that reason, Figure 4.1 displays the average bid over all 30 periods of the experiment. As players become more experienced, the average bids in both treatments decrease. The declining trend over the periods in each treatment is significant based on the estimation of a random effects model ( $p$-value $<0.01$ ), where the dependent variable is a bid and the

\footnotetext{
${ }^{3}$ We ran a random effects model on a constant and session dummy-variables separately for each treatment. Then we tested whether the constant coefficients are equal to the predicted theoretical values as in Table 4.1. We found that these differences are significant for both treatments ( $p$-value $<0.01)$.
} 
independent variable is an inverse of a period trend. Nevertheless, even in the last period of the experiment subjects overbid relative to the Nash equilibrium.

Table 4.1 - Average Statistics

\begin{tabular}{lrrc}
\hline \hline Treatment & Treatment P & Treatment E & Equilibrium \\
\hline Average Bid & $42.8(0.87)$ & $52.2(0.97)$ & 22.5 \\
Average Payoff & $-12.8(1.37)$ & $-22.2(1.38)$ & 7.5 \\
\hline \multicolumn{4}{l}{ Standard error of the mean in parentheses }
\end{tabular}

Figure 4.1 - Average Bid over Periods

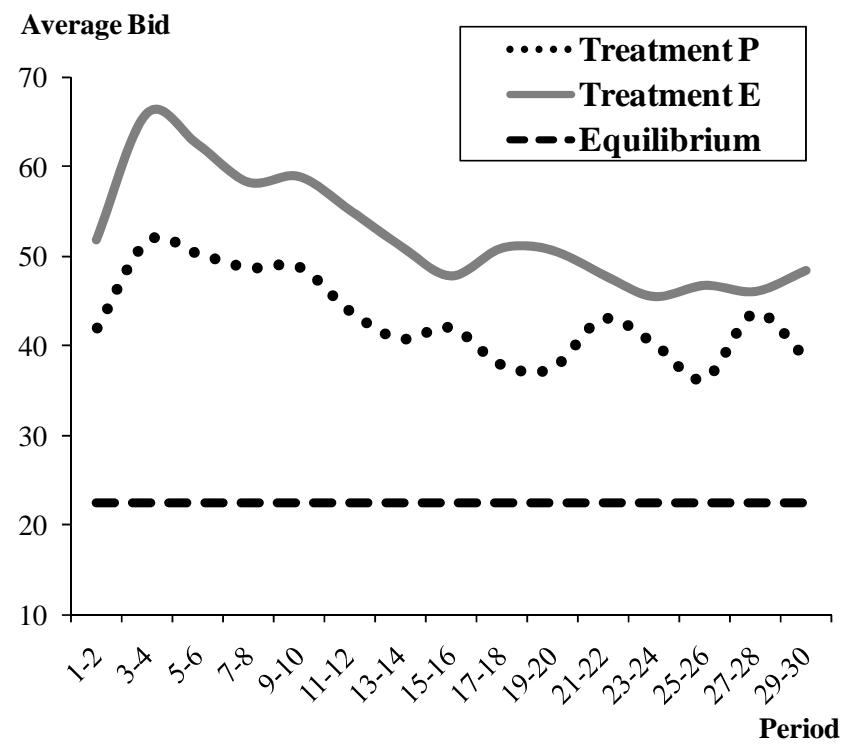

The presence of overbidding in numerous experimental studies, including our own, suggests that winning may be a component in a subject's utility (Sheremeta, 2008). In our experiment, at the end of each session we presented subjects with a trivial task similar to the thirty periods of bidding that they have completed in $\mathrm{E}$ and $\mathrm{P}$ treatments. The only difference is that now the prize was valued at zero francs. Again, subjects were explicitly told that they would have to pay their bids. Almost $50 \%$ of all subjects made positive bids, with $20 \%$ of subjects making bids higher than 30 francs (30 francs is equivalent to $\$ 0.5$ ). This finding suggests that a non-monetary value of winning may significantly contribute to overbidding in our experiment. 
The focus of this study is to determine if individual behavior is similar under the two theoretically-equivalent protocols commonly used in the literature. Table 4.1 indicates that subjects bid $22 \%$ more in the $\mathrm{E}$ treatment than in the $\mathrm{P}$ treatment (52.2 versus 42.8 ). This difference is significant based on the estimation of a random effects model, where the dependent variable is the bid and the independent variables are a period trend, session and treatment dummy-variables $(p$-value $=0.03)$. Moreover, the average bids in the $\mathrm{E}$ treatment are higher than the average bids in the $\mathrm{P}$ treatment over all periods of the experiment. The difference is significant in the first 15 periods $(p$-value $=0.08)$ and in the last 15 periods $(p$-value $=0.02)$ of the experiment.

One possible explanation of the treatment differences is due to loss aversion theory (Kahneman and Tversky, 1979). Nevertheless, it is unlikely that loss aversion can explain treatment differences because, relative to the initial endowment, subjects' decisions have identical consequences for gains and losses in both treatments. Additionally, the quantal response equilibrium model, designed to capture individual mistakes, is also unlikely to explain our results because in both treatments the strategy space is between 0 and 120 and therefore predictions for both treatments are exactly the same (McKelvey and Palfrey, 1995; Sheremeta, 2009).

Another possible explanation may be risk preferences. Table 4.2 reports the estimation results of four random effects models, where the dependent variable is the subject's bid and the independent variables are period, risk-aversion, and non-monetary variables. All regressions also include dummy-variables to capture session effects (not shown in the table) and lagged variables to capture the dynamic nature of the experiment. 
Table 4.2 - Determinants of Individual and Group Bids

\begin{tabular}{|c|c|c|c|c|}
\hline \multirow{2}{*}{ Dependent variable, bid } & \multicolumn{4}{|c|}{ Treatment } \\
\hline & $\mathrm{P}$ & $\mathrm{E}$ & $\mathrm{P}$ & $\mathrm{E}$ \\
\hline Specification & (1) & (2) & (3) & (4) \\
\hline period & $-0.19 *$ & $-0.37 * *$ & $-0.20^{*}$ & $-0.38 * *$ \\
\hline [period trend] & $(0.08)$ & $(0.10)$ & $(0.08)$ & $(0.10)$ \\
\hline risk-aversion & $-0.91^{* *}$ & -0.22 & $-0.87^{* *}$ & -0.47 \\
\hline [number of safe options A] & $(0.33)$ & $(0.44)$ & $(0.33)$ & $(0.44)$ \\
\hline non-monetary & & & $0.20 * *$ & $0.11^{* *}$ \\
\hline [bid in a contest with a prize of value zero] & & & $(0.03)$ & $(0.02)$ \\
\hline bid-lag & $0.61^{* *}$ & $0.56 * *$ & $0.56^{* *}$ & $0.53 * *$ \\
\hline [bid in period $t-1$ ] & $(0.03)$ & $(0.03)$ & $(0.03)$ & $(0.03)$ \\
\hline win-lag & 1.68 & 1.92 & 1.56 & 1.52 \\
\hline [1 if win in $t-1$ ] & $(1.62)$ & $(1.77)$ & $(1.58)$ & $(1.75)$ \\
\hline otherbid-lag & 0.01 & -0.01 & 0.01 & -0.01 \\
\hline [sum of opponents' bids in period $t-1$ ] & $(0.01)$ & $(0.01)$ & $(0.01)$ & $(0.01)$ \\
\hline Observations & 1392 & 1392 & 1392 & 1392 \\
\hline
\end{tabular}

The risk-aversion variable is defined as the number of safe options chosen by a subject in part one of the experiment (for the details see footnote 2). A higher number corresponds to more risk-aversion. Specifications (1) and (3) indicate that risk-aversion elicited from lotteries has significant negative influence on bidding behavior of subjects in the $\mathrm{P}$ treatment. On the other hand, risk-aversion does not have a significant effect on bidding behavior in the $\mathrm{E}$ treatment (specifications 2 and 4). One possible explanation of why risk-aversion seems to be important only in the $\mathrm{P}$ treatment is that subjects may perceive the endowment of 600 francs in the $\mathrm{E}$ treatment as a level of initial wealth. If this is the case, subjects with a high level of initial wealth may feel more inclined to disregard risks in the P treatment, and thus such subjects may be more inclined to overbidding in contests (Hillman and Katz, 1984). This explanation is consistent with Thaler and Johnson (1990), who document that after a prior gain, such as a large endowment, people behave as less risk-averse which leads to more aggressive bidding behavior. 
The non-monetary variable is defined as the amount of bidding in a contest with the prize valued at zero. The results indicate a significant and positive correlation between a subject's bid and the non-monetary variable, suggesting that winning is a component in a subject's utility and that non-monetary utility of winning is an important factor which may explain overbidding in contests.

\section{Conclusions}

Beyond the obvious benefit of understanding human behavior this study contributes to our understanding of several economic phenomena. A common topic in the finance literature is the concept of the Free Cash Flow Hypothesis (FCFH). Although the root problem in the FCFH is the misalignment of incentives in the principle-agent relationship, our research also shows that having a large reserve of "free cash" within a corporation may precipitate the wasteful use of resources (Jensen, 1986). Our study also yields important results for experimental methodology. Merlo and Schotter (1999) find that the manner in which subjects are paid may have an impact on what they choose to learn from the experiment. Similarly, our results have potential consequences for experimental methodology since they indicate that the manner in which subjects receive their endowments may have an impact on their decisions.

\section{References}

Anderson, L.R., \& Stafford, S.L. (2003). An experimental analysis of rent seeking under varying competitive conditions. Public Choice, 115, 199-216. 
Barut, Y., Kovenock, D., \& Noussair, C.N. (2002). A Comparison of Multiple-Unit All-Pay and Winner-Pay Auctions Under Incomplete Information. International Economic Review, 43, 675-708.

Davis, D., \& Reilly, R. (1998). Do many cooks always spoil the stew? An experimental analysis of rent seeking and the role of a strategic buyer. Public Choice, 95, 89-115.

Fischbacher, U. (2007). z-Tree: Zurich Toolbox for Ready-made Economic experiments. Experimental Economics, 10, 171-178.

Gneezy, U., \& Smorodinsky, R. (2006). All-Pay Auctions - An Experimental Study. Journal of Economic Behavior and Organization, 61, 255-275.

Hillman, A.L., \& Katz, E. (1984). Risk-averse rent seekers and the social cost of monopoly power. Economic Journal, 94, 104-110.

Holt, C.A., \& Laury, S.K. (2002). Risk Aversion and Incentive Effects. American Economic Review, 92, 1644-1655.

Jensen, M. (1986). Agency Costs of Free Cash Flow, Corporate Finance, and Takeovers. American Economic Review, 76, 323-329.

Kahneman, D., \& Tversky, A. (1979). Prospect Theory: An Analysis of Decision under Risk. Econometrica, 47, 263-291.

McKelvey, R., \& Palfrey, T. (1995). Quantal Response Equilibria for Normal Form Games. Games and Economic Behavior, 10, 6-38.

Merlo, A., \& Schotter, A., (1999). A Surprise-Quiz View of Learning in Economic Experiments, Games and Economic Behavior, 28, 25-54.

Morgan, J., Orzen, H., \& Sefton, M. (2008). Endogenous Entry in Contests. University of Nottingham, Working Paper.

Noussair, C., \& Jonathon, S. (2006). Behavior in all-pay auctions with incomplete information. Games and Economic Behavior, 55, 189-206.

Potters, J.C., De Vries, C.G., \& Van Linden, F. (1998). An experimental examination of rational rent seeking. European Journal of Political Economy, 14, 783-800.

Sheremeta, R.M. (2008). Experimental Comparison of Multi-Stage and One-Stage Contests. Purdue University, Working Paper.

Sheremeta, R.M. (2009). Contest Design: An Experimental Investigation. Economic Inquiry, forthcoming.

Sheremeta, R.M., \& Zhang, J. (2009). Can Groups Solve the Problem of Over-Bidding in Contests? Purdue University, Working Paper.

Thaler, R. H., \& Johnson, E. J. (1990). Gambling with the house money and trying to break even: The effects of prior outcomes on risky choices. Management Science, 36, 643-660.

Tullock, G. (1980). Efficient Rent Seeking. In James M. Buchanan, Robert D. Tollison, Gordon Tullock, (Eds.), Toward a theory of the rent-seeking society. College Station, TX: Texas A\&M University Press, pp. 97-112.

\section{(Not for publication)}

\section{Appendix: Treatment $\mathbf{P}$}




\section{GENERAL INSTRUCTIONS}

This is an experiment in the economics of strategic decision making. Various research agencies have provided funds for this research. The instructions are simple. If you follow them closely and make appropriate decisions, you can earn an appreciable amount of money.

The experiment will proceed in three parts. Each part contains decision problems that require you to make a series of economic choices which determine your total earnings. The currency used in Part 1 of the experiment is U.S. Dollars. The currency used in Part 2 and 3 of the experiment is francs. Francs will be converted to U.S. Dollars at a rate of $\mathbf{6 0}$ francs to $\_$${ }_{1}$ dollar. At the end of today's experiment, you will be paid in private and in cash. $\mathbf{1 2}$ participants are in today's experiment.

It is very important that you remain silent and do not look at other people's work. If you have any questions, or need assistance of any kind, please raise your hand and an experimenter will come to you. If you talk, laugh, exclaim out loud, etc., you will be asked to leave and you will not be paid. We expect and appreciate your cooperation.

At this time we proceed to Part 1 of the experiment.

\section{INSTRUCTIONS FOR PART 1}

\section{YOUR DECISION}

In this part of the experiment you will be asked to make a series of choices in decision problems. How much you receive will depend partly on chance and partly on the choices you make. The decision problems are not designed to test you. What we want to know is what choices you would make in them. The only right answer is what you really prefer.

For each line in the table in the next page, please state whether you prefer option A or option B. Notice that there are a total of $\mathbf{1 5}$ lines in the table but just one line will be randomly selected for payment. Each line is equally likely to be chosen, so you should pay equal attention to the choice you make in every line. After you have completed all your choices a token will be randomly drawn out of a bingo cage containing tokens numbered from $\mathbf{1}$ to 15. The token number determines which line is going to be paid.

Your earnings for the selected line depend on which option you chose: If you chose option A in that line, you will receive $\mathbf{\$ 1}$. If you chose option B in that line, you will receive either $\mathbf{\$ 3}$ or $\mathbf{\$ 0}$. To determine your earnings in the case you chose option B there will be second random draw. A token will be randomly drawn out of the bingo cage now containing twenty tokens numbered from 1 to 20. The token number is then compared with the numbers in the line selected (see the table). If the token number shows up in the left column you earn $\$ 3$. If the token number shows up in the right column you earn $\$ 0$.

\section{Are there any questions?}

\section{Participant ID}

\begin{tabular}{|l||c||c||c|}
\hline Decis & Optio & Option & Please \\
ion & $\mathbf{n ~ A ~}$ & $\mathbf{B}$ & choose \\
no. & & & A or B \\
\hline
\end{tabular}




\begin{tabular}{|c|c|c|c|}
\hline 1 & $\$ 1$ & \$3 never & $\begin{array}{l}\text { \$0 if } 1,2,3,4,5,6,7,8,9,10,11,12,13 \text {, } \\
14,15,16,17,18,19,20\end{array}$ \\
\hline 2 & $\$ 1$ & $\begin{array}{l}\$ 3 \text { if } 1 \text { comes out of the bingo } \\
\text { cage }\end{array}$ & $\begin{array}{l}\text { \$0 if } 2,3,4,5,6,7,8,9,10,11,12,13,14,15 \text {, } \\
16,17,18,19,20\end{array}$ \\
\hline 3 & $\$ 1$ & $\mathbf{\$ 3}$ if 1 or 2 comes out & $\begin{array}{l}\text { \$0 if } 3,4,5,6,7,8,9,10,11,12,13,14,15 \text {, } \\
16,17,18,19,20\end{array}$ \\
\hline 4 & $\$ 1$ & $\mathbf{\$ 3}$ if 1,2 , or 3 & $\begin{array}{l}\text { \$0 if } 4,5,6,7,8,9,10,11,12,13,14,15 \text {, } \\
16,17,18,19,20\end{array}$ \\
\hline 5 & $\$ 1$ & $\$ 3$ if $1,2,3,4$ & $\begin{array}{l}\text { \$o if } 5,6,7,8,9,10,11,12,13,14,15 \text {, } \\
16,17,18,19,20\end{array}$ \\
\hline 6 & $\$ 1$ & $\mathbf{\$ 3}$ if $1,2,3,4,5$ & $\begin{array}{l}\text { \$0 if } 6,7,8,9,10,11,12,13,14,15 \text {, } \\
16,17,18,19,20\end{array}$ \\
\hline 7 & $\$ 1$ & $\$ 3$ if $1,2,3,4,5,6$ & $\begin{array}{l}\text { \$0 if 7,8,9,10,11,12,13,14,15, } \\
16,17,18,19,20\end{array}$ \\
\hline 8 & $\$ 1$ & $\$ 3$ if $1,2,3,4,5,6,7$ & $\begin{array}{l}\text { \$0 if } 8,9,10,11,12,13,14,15 \text {, } \\
16,17,18,19,20\end{array}$ \\
\hline 9 & $\$ 1$ & $\$ 3$ if $1,2,3,4,5,6,7,8$ & $\begin{array}{l}\text { \$0 if } 9,10,11,12,13,14,15 \\
16,17,18,19,20\end{array}$ \\
\hline 10 & $\$ 1$ & $\$ 3$ if $1,2,3,4,5,6,7,8,9$ & $\mathbf{\$ 0}$ if $10,11,12,13,14,15,16,17,18,19,20$ \\
\hline 11 & $\$ 1$ & $\$ 3$ if $1,2,3,4,5,6,7,8,9,10$ & $\mathbf{\$ 0}$ if $11,12,13,14,15,16,17,18,19,20$ \\
\hline 12 & $\$ 1$ & $\$ 3$ if $1,2,3,4,5,6,7,8,9,10,11$ & $\mathbf{\$ 0}$ if $12,13,14,15,16,17,18,19,20$ \\
\hline 13 & $\$ 1$ & $\$ 3$ if $1,2,3,4,5,6,7,8,9,10,11,12$ & \$0 if $13,14,15,16,17,18,19,20$ \\
\hline 14 & $\$ 1$ & $\begin{array}{l}\text { \$3 if } 1,2,3,4,5,6,7,8,9,10 \\
11,12,13\end{array}$ & $\mathbf{\$ 0}$ if $14,15,16,17,18,19,20$ \\
\hline 15 & $\$ 1$ & $\begin{array}{l}\text { \$3 if 1,2,3,4,5,6,7,8,9,10 } \\
11,12,13,14\end{array}$ & \$o if $15,16,17,18,19,20$ \\
\hline
\end{tabular}

\section{INSTRUCTIONS FOR PART 2}

\section{YOUR DECISION}

The second part of the experiment consists of $\mathbf{3 0}$ decision-making periods. At the beginning of each period, you will be randomly and anonymously placed into a group of $\mathbf{4}$ participants. The composition of your group will be changed randomly every period. Each period, you and all other participants will be given an initial endowment of 
$\mathbf{1 2 0}$ francs. You will use this endowment to bid for a reward. The reward is worth $\mathbf{1 2 0}$ francs to you and the other three participants in your group. You may bid any integer number of francs between $\mathbf{0}$ and $\mathbf{1 2 0}$ (including 0.5 decimal points). An example of your decision screen is shown below.

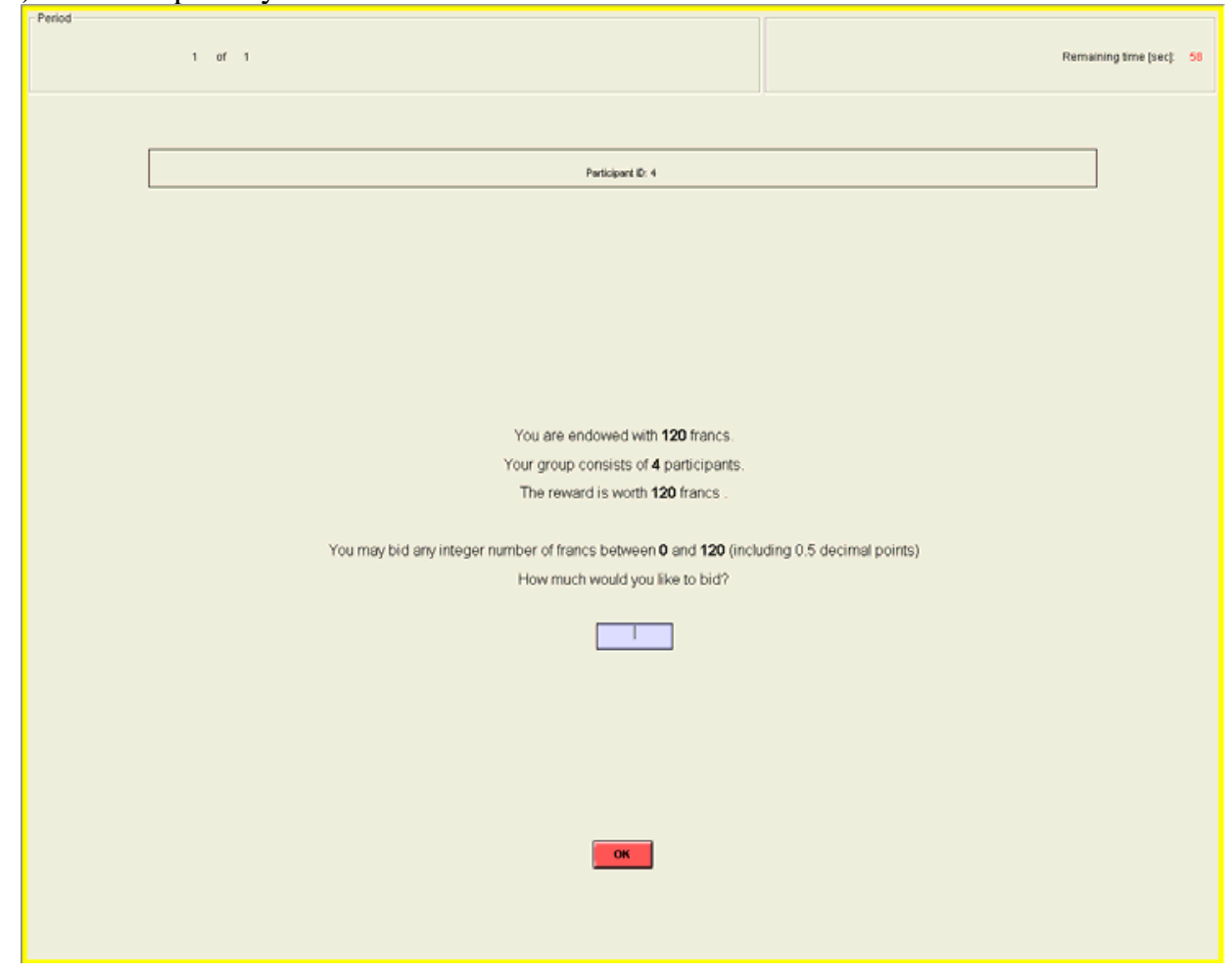

\section{YOUR EARNINGS}

After all participants have made their decisions, your earnings for the period are calculated. These earnings will be converted to cash and paid at the end of the experiment if the current period is one of the five periods that is randomly chosen for payment. If you receive the reward your period earnings are equal to your endowment plus the reward minus your bid. If you do not receive the reward your period earnings are equal to your endowment minus your bid.

If you receive the reward: $\quad$ Earnings $=$ Endowment + Reward - Your Bid $=120+120-$ Your Bid

If you do not receive the reward: $\quad$ Earnings $=$ Endowment - Your Bid $=120-$ Your Bid

The more you bid, the more likely you are to receive the reward. The more the other participants in your group bid, the less likely you are to receive the reward. Specifically, for each franc you bid you will receive one lottery ticket. At the end of each period the computer draws randomly one ticket among all the tickets purchased by 4 participants in the group, including you. The owner of the drawn ticket receives the reward of 120 francs. Thus, your chance of receiving the reward is given by the number of francs you bid divided by the total number of francs all 4 participants in your group bid.

Chance of receiving

the reward 4 Bids in your group

In case all participants bid zero, the reward is randomly assigned to one of the four participants in the group.

\section{Example of the Random Draw}

This is a hypothetical example used to illustrate how the computer is making a random draw. Let's say participant 1 bids 10 francs, participant 2 bids 15 francs, participant 3 bids 0 francs, and participant 4 bids 40 francs. Therefore, the computer assigns 10 lottery tickets to participant 1,15 lottery tickets to participant 2, 0 lottery tickets to participant 3 , and 40 lottery tickets for participant 4 . Then the computer randomly draws one lottery ticket out of 
$\mathbf{6 5}(10+15+0+40)$. As you can see, participant 4 has the highest chance of receiving the reward: $\mathbf{0 . 6 2}=\mathbf{4 0 / 6 5}$. Participant 2 has $0.23=15 / 65$ chance, participant 1 has $0.15=10 / 65$ chance, and participant 3 has $0=0 / 65$ chance of receiving the reward.

After all participants make their bids, the computer will make a random draw which will decide who receives the reward. Then the computer will calculate your period earnings based on your bid and whether you received the reward or not. At the end of each period, your bid, the sum of all bids in your group, whether you received the reward or not, and the earnings for the period are reported on the outcome screen as shown below. Once the outcome screen is displayed you should record your results for the period on your Personal Record Sheet under the appropriate heading.

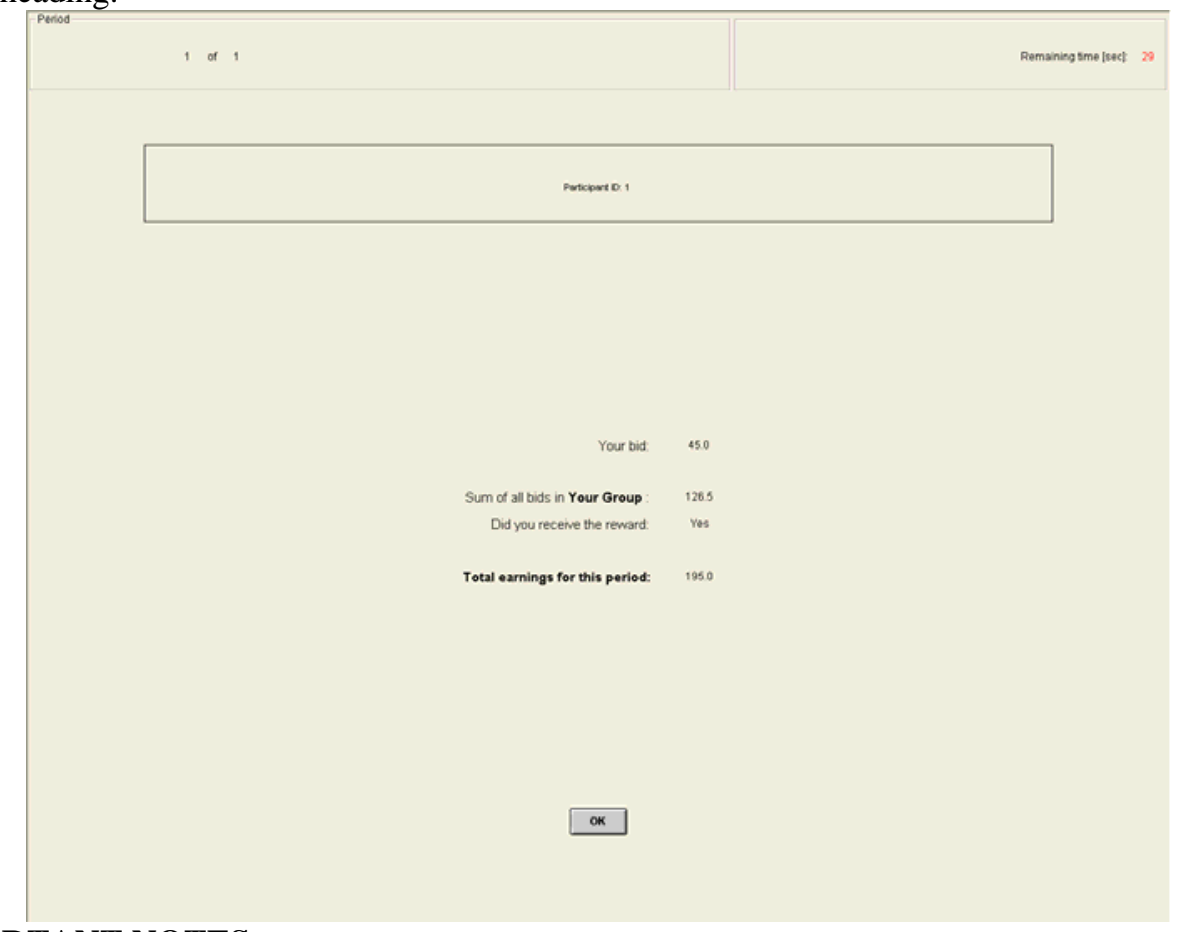

\section{IMPORTANT NOTES}

You will not be told which of the participants in this room are assigned to which group. At the beginning of each period you will be randomly re-grouped with three other participants to from a four-person group. You can never guarantee yourself the reward. However, by increasing your bid, you can increase your chance of receiving the reward. Regardless of who receives the reward, all participants will have to pay their bids. At the end of the experiment we will randomly choose $\mathbf{5}$ of the $\mathbf{3 0}$ periods for actual payment in Part $\mathbf{2}$ using a bingo cage. You will sum the total earnings for these 5 periods and convert them to a U.S. dollar payment.

\section{INSTRUCTIONS FOR PART 3}

The third part of the experiment consists of only 1 decision-making period. The rules for part $\mathbf{3}$ are the same as the rules for part 2 . At the beginning of the period, you will be randomly and anonymously placed into a group of four participants. You will be given an initial endowment of $\mathbf{1 2 0}$ francs. You will use this endowment to bid in order to be a winner. The only difference is that in part 4 the winner does not receive the reward. Therefore, the reward is worth $\mathbf{0}$ francs to you and the other three participants in your group. After all participants have made their decisions, your earnings for the period are calculated.

Earnings $=$ Endowment - Your Bid $=120-$ Your Bid

After all participants have made their decisions, your earnings for the period will be displayed on the outcome screen. Your earnings will be converted to cash and paid at the end of the experiment. 


\section{Economic Science Institute Working Papers}

2009

09-06 Cason, T., Savikhin, A. and Sheremeta, R. Cooperation Spillovers in Coordination Games.

09-05 Sheremeta, R. Contest Design: An Experimental Investigation.

09-04 Sheremeta, R. Experimental Comparison of Multi-Stage and One-Stage Contests.

09-03 Smith, A., Skarbek, D., and Wilson, B. Anarchy, Groups, and Conflict: An Experiment on the Emergence of Protective Associations.

09-02 Jaworski, T. and Wilson, B. Go West Young Man: Self-selection and Endogenous Property Rights.

09-01 Gjerstad, S. Housing Market Price Tier Movements in an Expansion and Collapse.

2008

08-10 Dickhaut, J., Houser, D., Aimone, J., Tila, D. and Johnson, C. High Stakes Behavior with Low Payoffs: Inducing Preferences with Holt-Laury Gambles.

08-09 Stecher, J., Shields, T. and Dickhaut, J. Generating Ambiguity in the Laboratory.

08-08 Stecher, J., Lunawat, R., Pronin, K. and Dickhaut, J. Decision Making and Trade without Probabilities.

08-07 Dickhaut, J., Lungu, O., Smith, V., Xin, B. and Rustichini, A. A Neuronal Mechanism of Choice.

08-06 Anctil, R., Dickhaut, J., Johnson, K., and Kanodia, C. Does Information Transparency Decrease Coordination Failure?

08-05 Tila, D. and Porter, D. Group Prediction in Information Markets With and Without Trading $\underline{\text { Information and Price Manipulation Incentives. }}$

08-04 Caginalp, G., Hao, L., Porter, D. and Smith, V. Asset Market Reactions to News: An Experimental Study.

08-03 Thomas, C. and Wilson, B. Horizontal Product Differentiation in Auctions and Multilateral Negotiations.

08-02 Oprea, R., Wilson, B. and Zillante, A. War of Attrition: Evidence from a Laboratory Experiment on Market Exit.

08-01 Oprea, R., Porter, D., Hibbert, C., Hanson, R. and Tila, D. Can Manipulators Mislead Prediction Market Observers? 